Check for updates

Cite this: RSC Adv., 2019, 9, 35895

Received 3rd September 2019

Accepted 21st October 2019

DOI: 10.1039/c9ra07017f

rsc.li/rsc-advances

\section{Acetone fractionation: a simple and efficient method to improve the performance of lignin for dye pollutant removal}

\author{
Hao Li, (D) abc Ze Yuan, ${ }^{a}$ Yuyu Xing, ${ }^{a}$ Jiarong Li, ${ }^{a}$ Jing Fang, ${ }^{\text {ac }}$ Lifang Chang ${ }^{a}$ \\ and Chunli Li*a
}

\begin{abstract}
In this work, it was found that the adsorption capacity of lignin to cationic dye (methylene blue, MB) from aqueous solution could be significantly improved by simple acetone fractionation. The removal efficiency of MB by acetone insoluble kraft lignin (AIKL) was 10 times that of unfractionated kraft lignin (KL). And the maximum capacity of AIKL could reach up to $623.4 \mathrm{mg} \mathrm{g}^{-1}$. And the high removal rate could be achieved even at low concentrations. The effects of ionic strength, temperature, adsorbent dosage were systematically investigated. Adsorption kinetics showed the adsorption behavior obeyed the pseudosecond-order kinetic model. The equilibrium data was more consistent with the Langmuir isotherm model. Thermodynamic analyses proved that the adsorption was a spontaneous and endothermic physisorption process. In addition, the reasons for the enhanced adsorption effect by fractionation were clarified based on characterization by FT-IR. The enhancement of $\pi-\pi$ interaction between AIKL and MB caused by fractionation plays an important role in the adsorption process.
\end{abstract}

\section{Introduction}

The discharge of wastewater containing dyes is a key environmental challenge. ${ }^{1}$ Not only do they cause damage to the ecosystem but they are also harmful to human beings. ${ }^{2}$ Methylene blue (MB) is one of the most commonly used cationic dyes. ${ }^{3}$ It could cause many harmful effects on human beings, such as nausea, mental confusion, jaundice, quadriplegia and tissue necrosis. ${ }^{4}$ Consequently, MB must be removed from wastewater effluents before discharging.

Various techniques have been used to remove dyes that include biodegradation, flocculation-coagulation, chemical oxidation, ion-exchange, reverse osmosis, ultrafiltration and adsorption. ${ }^{5-9}$ Among these techniques, adsorption is considered to be efficient and economical. ${ }^{10-12}$ Activated carbon was a commonly adsorbent for dye removal, ${ }^{13}$ while the high cost limited its application on a larger scale. ${ }^{14}$

Recently, low cost adsorbents have been developed such as natural materials, agricultural by-products and industrial solid wastes. ${ }^{15-19}$ Especially, they were more suitable for treating solutions containing dilute $\mathrm{MB}$ concentrations. ${ }^{20}$ Due to the

\footnotetext{
${ }^{a}$ National-Local Joint Engineering Laboratory for Energy Conservation in Chemical Process Integration and Resources Utilization, School of Chemical Engineering and Technology, Hebei University of Technology, Tianjin, China. E-mail: ctstfj@hebut. edu.cn; lichunli_hebut@126.com

${ }^{b}$ Guangdong Provincial Key Lab of Green Chemical Product Technology, Wushan Road, Guangzhou, PR China

'Tianjin Key Laboratory of Chemical Process Safety, China
}

advantages of low cost, biodegradability, usability, renewability and high adsorption efficiency, they are considered promising potential alternatives to conventional methods of removing MB.

Lignin is considered as an excellent candidate among the low-cost class. ${ }^{21-23}$ It is one of the most abundant natural polymers, second only to cellulose. ${ }^{24}$ Many researchers have reported the feasibility of using various lignin as the precursors of absorbents for MB removal. A formaldehyde modified formic lignin and a lignin-chitosan extruded blends ${ }^{25}$ shown the adsorption capacity of about $35 \mathrm{mg} \mathrm{g}^{-1}$ for MB. Alkali extracted lignin, chitosan-kraft lignin composites, ${ }^{26}$ and the activated carbon $^{27}$ prepared from lignin exhibited higher adsorption capacity among 121-147 $\mathrm{mg} \mathrm{g}^{-1}$. After deacetylated and fractionated, the adsorption capacity of acetic acid lignin for $\mathrm{MB}$

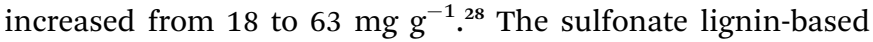
hydrogels were prepared by grafting sulfonic groups on $\mathrm{KL}$ and the adsorption capacity could been improved to $495 \mathrm{mg}$ $\mathrm{g}^{-1} \cdot{ }^{29}$

However, kraft technology was used by mostly pulp mills for pulp production, and thus KL is easier to use for value-added production. ${ }^{30}$ Although KL can be directly used as a promising adsorbent owing to their insolubility in water, its application for MB adsorption did not arouse much attention. To our delight, the authors recently found that the performance of KL for $\mathrm{MB}$ removal could be significantly enhanced just by easy fractionation with acetone.

Acetone was extensively used to dissolve lignin as a facile solvent. As we know, the acetone soluble kraft lignin (ASKL) has been widely reported in many applications, due to the soluble 
lignin is easier to process and react chemically in solution. For example, ASKL could improve the thermal stability of its blends with polyethylene, due to the better antioxidant activity. ${ }^{\mathbf{3 1}}$ Also, ASKL is more easily to form lignin colloidal spheres with high sun protection factor. ${ }^{32}$ ASKL shown its tremendous potential for thermoplastic materials relations. ${ }^{33}$ Comparing to the reports for the application of ASKL, the application of AIKL is rarely reported. Obviously, the usage of AIKL could improve the utilization efficiency for the all-components of lignin. As a biosorbent coming from the abandoned biomass, AIKL was obtained just by a simple physical chemistry process without any chemical modification. Thus, it has the advantage of cost effective, biodegradability, high usability, minimization of waste, in addition to good adsorption efficiency.

In this study, KL was fractionated by acetone to ASKL and AIKL. Then, the first application of the AIKL, as an adsorption material for MB was investigated. The influence of adsorption parameters such as initial dye concentration, contact time, temperature, ionic strength was investigated. The adsorption process was studied by equilibrium data on batch adsorption, and the adsorption kinetics were calculated to establish the efficiency of AIKL. The adsorption behavior of KL and ASKL were also reported as reference. The interactions between the lignin and MB was investigated by FTIR, and then the reason for the performance improvement by solvent fractionation was deduced.

\section{Materials and methods}

\subsection{Materials}

KL (softwood), purchased from the Quanlin Paper Mill in Shandong Province of China, was obtained from the straw. Cationic dye MB was supplied by Tianjin Fenghua Chemical Reagent Technology Co., Ltd. All the reagents were analytical reagent grade and working solutions were prepared by distilled water.

\subsection{Methods}

2.2.1. Fractionation of kraft lignin. The raw KL was suspended in acetone solutions $(50 \mathrm{~g} / 500 \mathrm{~mL})$ with a concentration of $99.5 \%$, and the suspension was stirred $24 \mathrm{~h}$ at $30{ }^{\circ} \mathrm{C}$. The solid residue (AIKL) was then removed by filtration. ASKL was recovered by evaporating the supernatant solvent in a rotary evaporator at $100{ }^{\circ} \mathrm{C}$. Both of the AIKL and ASKL were then followed by drying in a vacuum oven at room temperature for $12 \mathrm{~h}$. The yields of ASKL and AIKL were $46.6 \%$ and $53.4 \%$, respectively.

2.2.2. Batch adsorption experiments. The working solutions were obtained by diluting stock solution of $\mathrm{MB}\left(1 \mathrm{~g} \mathrm{~L}^{-1}\right)$ to the desired concentrations for adsorption experiments. All adsorption experiments were performed at on a constant temperature shaker with $0.04 \mathrm{~g}$ of the lignin in a $100 \mathrm{~mL}$ conical flask containing $50 \mathrm{~mL}$ of dye solutions. The characteristic absorbance was measured by a UV-vis spectrometer (Purkinje Genera, China) to determine the concentration of the dyes after adsorption, and the characteristic absorbance of MB was $664 \mathrm{~nm}$. The adsorption capacity of MB on lignin, $Q_{\mathrm{e}}\left(\mathrm{mg} \mathrm{g}^{-1}\right)$ was calculated according to the following equation:

$$
Q_{\mathrm{e}}=\frac{\left(C_{\mathrm{o}}-C_{\mathrm{e}}\right) V}{m}
$$

where, $C_{\mathrm{e}}$ and $C_{\mathrm{o}}$ are the equilibrium and initial concentrations $\left(\mathrm{mg} \mathrm{L}^{-1}\right.$ ) of the adsorbed dye solutions, respectively; $V$ is the solution volumes (L) of the tested solution, respectively, $m$ is the dry weight $(\mathrm{g})$ of the lignin adsorbent.

In the solution with methylene blue concentration of $120 \mathrm{mg} \mathrm{L}^{-1}$ at $30{ }^{\circ} \mathrm{C}$, the lignin concentration was changed from $0.1 \mathrm{~g} \mathrm{~L}^{-1}$ to $12.0 \mathrm{~g} \mathrm{~L}^{-1}$ to investigate the effect of the amount of adsorbent to adsorption capacity of MB. Under the same experimental conditions, the influences of adding one electrolytes ( $\mathrm{NaCl}$ ) were investigated. The $\mathrm{MB}$ adsorption effected by temperature were measured in three different temperature $\left(30,40\right.$ and $\left.50{ }^{\circ} \mathrm{C}\right)$. The MB adsorption kinetics were measured in $30{ }^{\circ} \mathrm{C}$, samples collection time is from 5 minutes to 24 hours. The adsorption isotherms were measured at $30{ }^{\circ} \mathrm{C}$, the contact time was $24 \mathrm{~h}$, and the initial MB concentration was in the range from 10 to $300 \mathrm{mg} \mathrm{L}^{-1}$.

\subsubsection{Isotherm models}

2.2.3.1. Langmuir isotherm model. The Langmuir and Freundlich models were used to interpret the equilibrium absorption data, respectively.

The Langmuir expression and its linearized form are calculated according to the following equations:

$$
\begin{gathered}
q_{\mathrm{e}}=\frac{q_{\mathrm{m}} K_{\mathrm{L}} C_{\mathrm{e}}}{1+K_{\mathrm{L}} C_{\mathrm{e}}} \\
\frac{C_{\mathrm{e}}}{q_{\mathrm{e}}}=\frac{1}{q_{\mathrm{m}} K_{\mathrm{L}}}+\frac{C_{\mathrm{e}}}{q_{\mathrm{m}}}
\end{gathered}
$$

where $K_{\mathrm{L}}$ is the Langmuir constant $\left(\mathrm{L} \mathrm{mg}^{-1}\right)$ which was connected to the affinity of binding sites, $q_{\mathrm{e}}\left(\mathrm{mg} \mathrm{g}^{-1}\right)$ represents the equilibrium adsorption capacity per gram adsorbent to $\mathrm{MB}, C_{\mathrm{e}}$ $\left(\mathrm{mg} \mathrm{L}^{-1}\right)$ represents the equilibrium concentration of $\mathrm{MB}$, and $q_{\mathrm{m}}\left(\mathrm{mg} \mathrm{g}^{-1}\right)$ represents the theoretical maximum of adsorption capacity. Thus, the validity of the Langmuir model was confirmed by the linear plot of $C_{\mathrm{e}} / q_{\mathrm{e}}$ versus $C_{\mathrm{e}}$. And $R_{\mathrm{L}}$ is defined as:

$$
R_{\mathrm{L}}=\frac{1}{1+K_{\mathrm{L}} C_{\mathrm{o}}}
$$

where $C_{\mathrm{o}}\left(\mathrm{mg} \mathrm{L}^{-1}\right)$ represents the initial concentration in the liquid phase; $K_{\mathrm{L}}\left(\mathrm{L} \mathrm{mg}^{-1}\right)$ represents the Langmuir constant; $R_{\mathrm{L}}$ is the dimensionless parameter of the equilibrium or adsorption intensity.

2.2.3.2. Freundlich isotherm model. The Freundlich expression and its linearized form are calculated according to the following equations:

$$
\begin{gathered}
q_{\mathrm{e}}=K_{\mathrm{F}} C_{\mathrm{e}^{\frac{1}{n}}} \\
\ln q_{\mathrm{e}}=\ln K_{\mathrm{F}}+\ln \frac{C_{\mathrm{e}}}{n}
\end{gathered}
$$

where $n$ is the heterogeneity factor and the $1 / n$ value related to the adsorption intensity. $K_{\mathrm{F}}$ is the Freundlich constant $\left(\mathrm{mg} \mathrm{g}^{-1}\right)$ 
and $K_{\mathrm{F}}$ value is related to the adsorption capacity. A plot of $\ln q_{\mathrm{e}}$ versus $\ln C_{\mathrm{e}}$ shows a straight line, where $K_{\mathrm{F}}$ and $1 / n$ are determined by intercept and slope respectively.

2.2.4. Adsorption kinetics. In order to explore the adsorption kinetics, pseudo-first-order (7) and pseudo-second-order (8) kinetic equations were used to analyze adsorption kinetic data:

$$
\begin{gathered}
\ln \left(q_{\mathrm{e}}-q_{\mathrm{t}}\right)=\ln q_{\mathrm{e}}-k_{1} t \\
\frac{t}{q_{t}}=\frac{1}{k_{2} q_{\mathrm{e}}^{2}}+\frac{t}{q_{\mathrm{e}}}
\end{gathered}
$$

where $q_{\mathrm{e}}$ and $q_{t}$ are the adsorption capacity of methylene blue adsorbed $\left(\mathrm{mg} \mathrm{g}^{-1}\right)$ and time $t(\mathrm{~min})$ at equilibrium, respectively. $k_{1}\left(\mathrm{~min}^{-1}\right)$ and $k_{2}\left(\mathrm{~g} \mathrm{mg}^{-1} \mathrm{~min}\right)$ are the rate constants of pseudofirst-order and pseudo-second-order kinetics equations, respectively.

2.2.5. Thermodynamic study. The thermodynamic parameters were confirmed by van't Hoff analysis to elucidate the thermodynamic origins of the adsorption process. Through van't Hoff equation, the relationship between Langmuir adsorption constant $K_{\mathrm{L}}$ and temperature $T$ were described shown as follows:

$$
\ln K_{\mathrm{L}}=\frac{\Delta S}{R}-\frac{\Delta H}{R T}
$$

where $T(\mathrm{~K})$ is the absolute temperature, $R\left(8.314 \mathrm{~J} \mathrm{~mol}^{-1} \mathrm{~K}\right)$ is the universal gas constant, $\Delta H\left(\mathrm{~J} \mathrm{~mol}^{-1} \mathrm{~K}^{-1}\right)$ is the enthalpy change; and $\Delta S\left(\mathrm{~J} \mathrm{~mol}^{-1} \mathrm{~K}^{-1}\right)$ is the entropy change. $\Delta H$ and $\Delta S$ were calculated from the slope and intercept of linear plots of $\ln K_{\mathrm{L}} v s . \mathrm{T}^{-1}$, respectively.

The Gibbs energy change, $\Delta G\left(\mathrm{~J} \mathrm{~mol}^{-1}\right)$, was estimated from the following relationship:

$$
\Delta G=-R T \ln K_{\mathrm{L}}
$$

\section{Results and discussion}

\subsection{Effects of adsorbent dosage and treating effect}

Fig. 1 shows the effects of the sample dosage of KL, ASKL and AIKL on MB adsorption. The removal rate of MB increased with

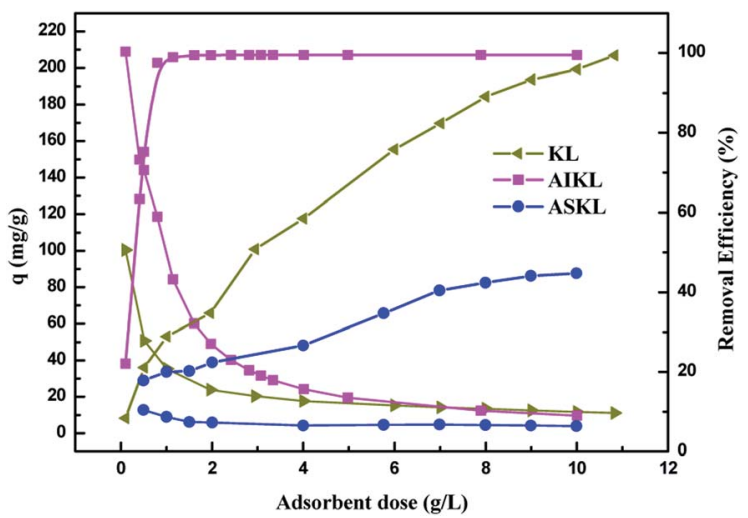

Fig. 1 Effect of the adsorbent dosage on the adsorption of MB (initial $\mathrm{C}_{\mathrm{MB}}: 0.12 \mathrm{~g} \mathrm{~L}^{-1}$, temp.: $30^{\circ} \mathrm{C}$ ). the increasing adsorbent dosage because of the increase of the binding sites in adsorption. And the adsorption capacity of $\mathrm{MB}$ decreases with increasing adsorbent. This is owing to the higher adsorbent dosage could provide a large excess of the active sites which causing a decrease in the utility of active sites. Obviously, AIKL is superior to KL and ASKL in MB removal under the lower dosage. The removal rate of $\mathrm{MB}$ by AIKL could approached $100 \%$ when the dosage was $1.8 \mathrm{~g} \mathrm{~L}^{-1}$. However, for the same removal rate, no less than $11 \mathrm{~g} \mathrm{~L}^{-1}$ of $\mathrm{KL}$ was needed. And the removal rate of $\mathrm{MB}$ was only $44 \%$ while the dosage of ASKL was up to $10 \mathrm{~g} \mathrm{~L}^{-1}$. It means that, compared to KL and ASKL, only a little AIKL was needed for MB removal.

From UV-vis spectra (Fig. 2), the characteristic peaks of the MB show obvious decrease or completely disappear after removal by the three samples at the same dosage. Meantime, the colour of solution (inset of Fig. 2) were also getting lighter. Especially, the solutions treated by AIKL were almost completely decolorized, indicating the most efficient removal of the MB from water.

\subsection{Adsorption kinetics}

The time-dependent absorption of MB on three kinds of lignin samples were measured, and results are presented in Fig. 3. The adsorption of $\mathrm{MB}$ on the three samples start out fast, then slow down and finally reach to equilibrium. Steep slope of $\mathrm{MB}$ adsorption on the three samples at the initial period indicated the instantaneous adsorption which might be due to the abundant adsorption sites for MB.

The values of $k_{1}$ was calculated by the plots of $\ln \left(q_{\mathrm{e}}-q_{t}\right)$ versus $t$ (Fig. 5). The linear plots of $t / q_{t}$ versus $t$ (Fig. 4), and values of $k_{2}$ and $q_{\mathrm{e}}$ were calculated from the intercept and slope of the plots. The experimental adsorption capacities and characteristic parameters calculated were shown in Table 1 . The correlation coefficients $\left(R^{2}\right)$ for pseudo-second-order kinetics were better than that for pseudo-first-order kinetics. Furthermore, the $q_{\mathrm{e}}$ calculated from pseudo-second-order kinetic model was more consistent with the experimental data $\left(q_{\text {ex }}\right)$ than the pseudo-first-order kinetic model. Thus, the pseudosecond-order kinetics could describe the adsorption process more reasonably in comparison to the pseudo-first-order models.

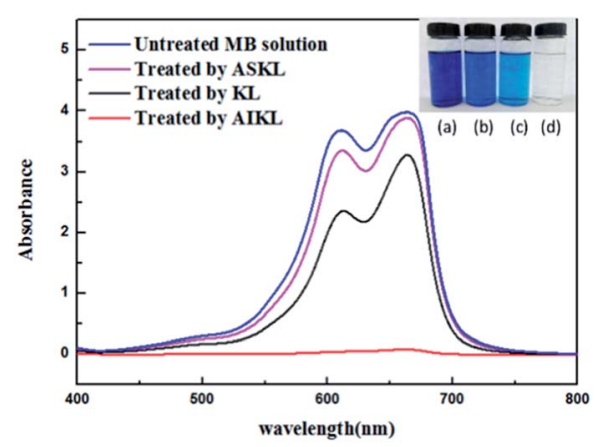

Fig. 2 UV-vis absorption spectra of the MB solution before and after treating. Inset: color of MB solution adsorbed by: (a) the control, (b) ASKL, (c) KL, (d) AIKL. 


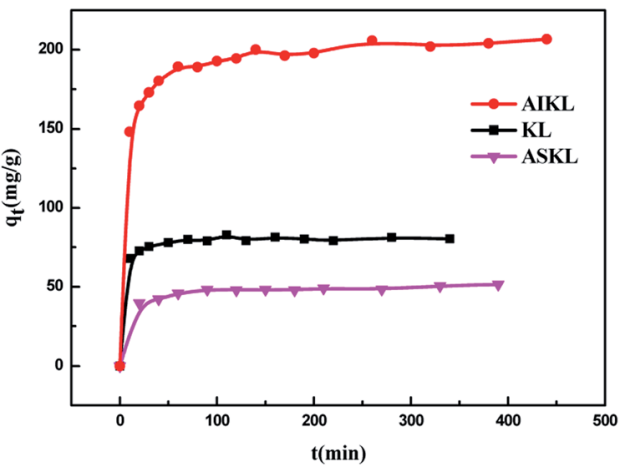

Fig. 3 Effect of contact time on the adsorption of MB onto KL, ASKL and AIKL at $30^{\circ} \mathrm{C}$.

From Fig. 3, the time required for ASKL and KL to reach the adsorption equilibrium was less than AIKL. The adsorption process of $\mathrm{MB}$ on AIKL in the following stage need a relative long time. Also, the values of $k_{2}$ for KL and ASKL was higher than AIKL, indicating the adsorption process of the latter system was slow.

As a matter of fact, AIKL is easier to form larger aggregates due to it is more hydrophobic. Thus, there are more inner cavities or porous structures formed by aggregation. The adsorption sites in the inner space of AIKL aggregates was more tough to contact $\mathrm{MB}$, resulting in the longer adsorption equilibrium time and a lower adsorption rate.

\subsection{Adsorption isotherms}

Fig. 6 shows the adsorption isotherms of MB on KL, AIKL and ASKL and the uniformity and non-uniformity of adsorbent surface can be obtained by its shape. The adsorption capacity of MB on the three samples all increased with the increase of the equilibrium concentration and finally reached the saturation value. At the same equilibrium concentration, the adsorption capacity of MB on AIKL is much higher than that of KL, while the adsorption capacity of MB on ASKL is a little lower than KL. It is noteworthy that the absorption amount of $\mathrm{MB}$ on AIKL increased almost vertically with initial lower dye concentration,

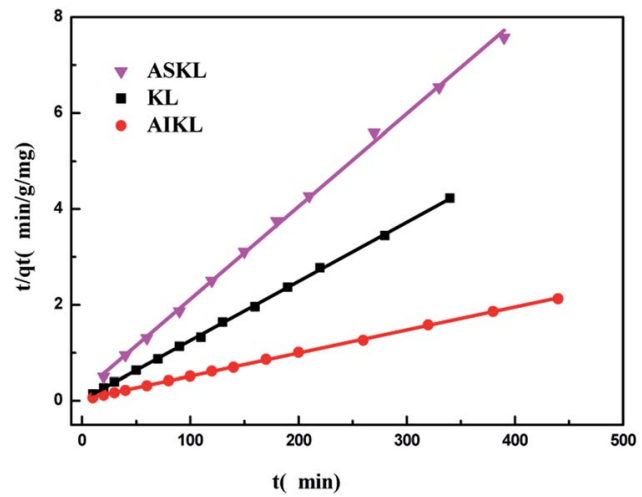

Fig. 4 Second-order kinetic equation for adsorption of methylene blue on to $K L, A S K L$ and AIKL. making the AIKL have the advantage of removing lower concentration wastewater.

Fig. 7 shows the Langmuir plot for the adsorption of MB onto AIKL, KL and ASKL, from the linearized Langmuir equation. The Langmuir constants $K_{\mathrm{L}}$ and $q_{\mathrm{m}}$ are shown in Table 2, the equilibrium data has a higher correlation coefficient and well adapted of Langmuir model. The adsorption isotherm data was also analyzed by Freundlich model, but its poor fit (Table 2) indicated that it was not suitable for MB/lignin system.

Due to the better fits with Langmuir isotherm, the adsorption of MB onto the three adsorbents was monolayer physical adsorption on homogeneous surfaces.

The separation factor $R_{\mathrm{L}}$, calculated by eqn (4), was the dimensionless parameter of the adsorption intensity. The type of the isotherm was either unfavorable $\left(R_{\mathrm{L}}>1\right)$, linear $\left(R_{\mathrm{L}}=1\right)$, favorable $\left(0<R_{\mathrm{L}}<1\right)$ or irreversible $\left(R_{\mathrm{L}}=0\right)$ could be inferred by the value of $R_{\mathrm{L}}$ (eqn (4)). For adsorption of $\mathrm{MB}$ onto three adsorbents in this study, all the $R_{\mathrm{L}}$ values (Table 2) are in the range of 0.0188 to 0.4615 , indicating the adsorption is a favorable process.

MB adsorption had been studied by a variety of different adsorbents. MB adsorption had been studied by a variety of different adsorbents. Table 3 compared the maximum adsorption capacity of MB for various biomass adsorbents. Compared with the other modified natural materials such as banana pseudostem, Platanus orientalis leaf and Luffa cylindrica fibers, ${ }^{37-39}$ the advantage of AIKL is that the aromatic ring of lignin could have $\pi-\pi$ interaction with $\mathrm{MB}$ which is beneficial to the adsorption. As for lignin-based hydrogels prepared by crosslinking poly used methyl vinyl ether co-maleic acid, ${ }^{35}$ the preparation of AIKL only requires one step of dissolution, the entire process is simple to operate and can be easily scalable.

Although its adsorption capacity is not the highest, it possesses the merits of renewable and easy to mass produce. Thus, AIKL could be a promising low-cost adsorbent for $\mathrm{MB}$ removal from solution.

According to the Langmuir equation, the maximum uptake capacity of MB on AIKL were $200.0 \mathrm{mg} \mathrm{g}^{-1}$. While, the saturated adsorption capacity of KL and ASKL were $79.9 \mathrm{mg} \mathrm{g}^{-1}$ and $49.9 \mathrm{mg} \mathrm{g}^{-1}$, respectively. The saturated adsorption capacity of

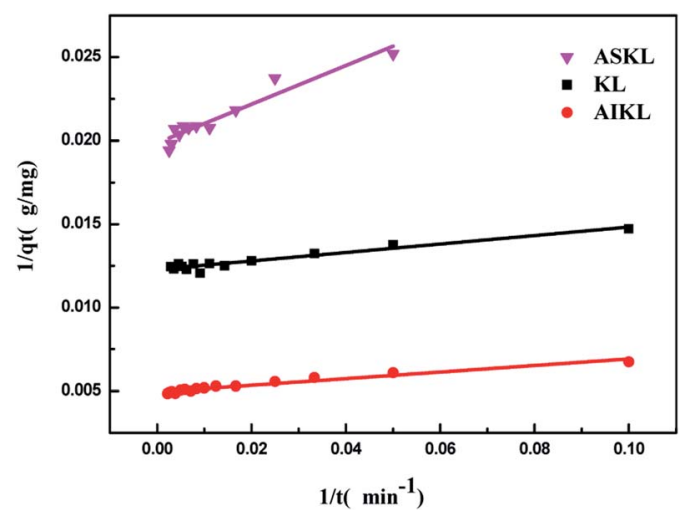

Fig. 5 Pseudo-first-order kinetic fit curve of MB adsorption on AIKL, $\mathrm{KL}$ and $\mathrm{ASKL}$. 
Table 1 Adsorption kinetic parameters for the adsorption of MB onto AIKL, ASKL and KL

\begin{tabular}{|c|c|c|c|c|c|c|c|}
\hline Sorbent & \multicolumn{4}{|c|}{ Pseudo-first-order } & \multicolumn{3}{|c|}{ Pseudo-second-order } \\
\hline KL & 2.0717 & 81.4332 & 0.9293 & 80.3529 & 0.0084 & 80.9717 & 0.9996 \\
\hline ASKL & 5.8524 & 50.3778 & 0.9113 & 51.4837 & 0.0021 & 51.6796 & 0.9985 \\
\hline
\end{tabular}

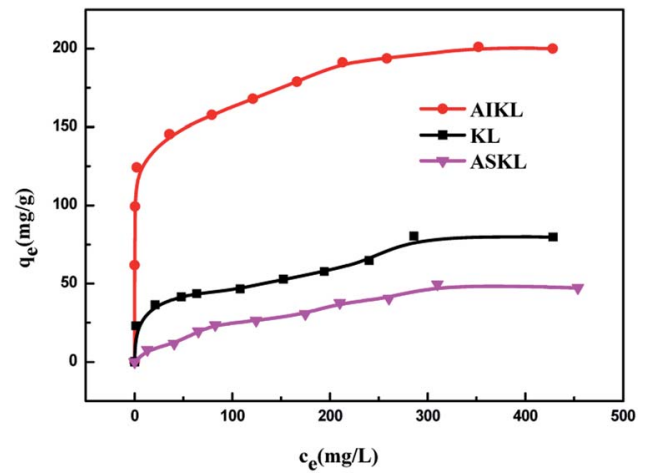

Fig. 6 Isotherms of $\mathrm{MB}$ adsorption onto $\mathrm{KL}, \mathrm{AIKL}$ and $\mathrm{ASKL}$ at $30^{\circ} \mathrm{C}$.

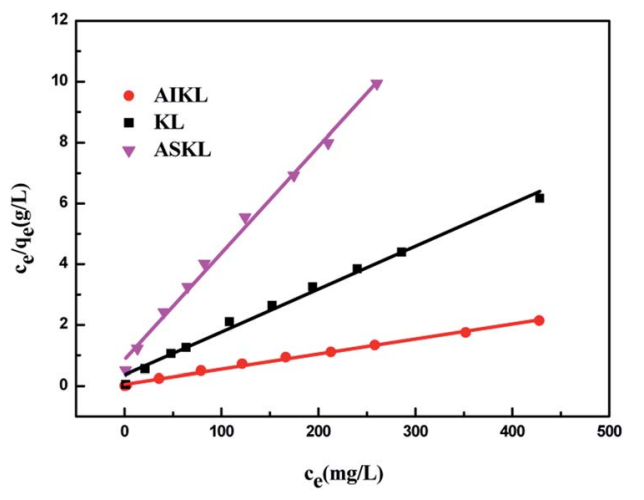

Fig. 7 Langmuir plot of adsorption of $M B$ onto KL, ASKL and AIKL.

AIKL for MB increased about 2.5 times than KL. It is worth nothing that, the data of adsorption capacities for the three samples could not be explained by the conservation of mass. When the KL was fractionated by acetone, the yields of ASKL and AIKL were $46.7 \%$ and $53.3 \%$, respectively. If we sum up the adsorption capacities ASKL and AIKL in proportion, that is:

$$
q_{\mathrm{e} 1} \times \omega_{1}+q_{\mathrm{e} 2} \times \omega_{2}=Q_{\mathrm{KL}}^{\prime}>Q_{\mathrm{KL}}
$$

where $q_{\mathrm{e} 1}$ and $q_{\mathrm{e} 2}$ are the adsorption capacity $\left(\mathrm{mg} \mathrm{g}^{-1}\right)$ of MB by AIKL and ASKL, respectively. The $\omega_{1}$ and $\omega_{2}$ are the yields of AIKL and ASKL, respectively. The $Q_{\mathrm{KL}}^{\prime}$ represents the adsorption capacity calculated by mass conservation. $Q_{\mathrm{KL}}$ is the adsorption capacity of KL. It could be found $Q_{\mathrm{KL}}^{\prime}\left(118.6 \mathrm{mg} \mathrm{g}^{-1}\right)$ is much larger than $Q_{\mathrm{KL}}\left(79.9 \mathrm{mg} \mathrm{g}^{-1}\right)$. Obviously, this did not obey the mass conservation. Thus, there must be some underlying reasons for explain this unpredictable result, which was described in the following paragraphs.

\subsection{Effects of operating conditions on MB adsorption}

3.4.1. Effect of temperature. Dye effluents are usually produced at relatively high temperatures. ${ }^{37}$ To figure out the influence of temperature, adsorption experiments were carried out at 30,40 and $50{ }^{\circ} \mathrm{C}$, respectively. As shown in Fig. 8, the MB adsorption capacity increased significantly from 200.0 to $345.0 \mathrm{mg} \mathrm{g}^{-1}$ with the increase in temperature from 30 to $50^{\circ} \mathrm{C}$. Which means the AIKL could be a high-efficiency adsorbent for MB removal at higher temperatures. The thermodynamic parameters calculated from eqn (9) and (10) are listed in Table 4. As we know, the change in free energy for physical absorption is between -20 and $0 \mathrm{~kJ} \mathrm{~mol}^{-1}$. ${ }^{40}$ The values of $\Delta G$ obtained in this study are within this ranges, indicating that the adsorption is physisorption. Moreover, with the increase of temperature the value of $\Delta G$ became more negative, indicating that a higher temperature was more favorable to the adsorption process (Fig. 9).

The positive enthalpy changes suggest that the adsorption process of MB onto AIKL is endothermic. Generally, adsorption was exothermic processes due to the binding of solute and adsorbent, and the adsorption capacity decreases with the increase of temperature. A reasonable explanation for the positive enthalpy changes of this system was the high energy water molecules were released from the desolvation of $\mathrm{MB}$ and

Table 2 The adsorption parameters of Langmuir and Freundlich model for the adsorption of MB onto AIKL, KL and ASKL

\begin{tabular}{|c|c|c|c|c|c|c|c|}
\hline Sorbent & \multicolumn{4}{|c|}{ Langmuir isotherm parameters } & \multicolumn{3}{|c|}{ Freundlich isotherm parameters } \\
\hline KL & 79.9361 & 0.0398 & 0.9910 & $0.0537-0.3620$ & 21.2886 & 4.587 & 0.9453 \\
\hline ASKL & 49.8753 & 0.0233 & 0.9940 & $0.0789-0.4615$ & 1.3265 & 1.713 & 0.9753 \\
\hline
\end{tabular}


Table 3 Comparison of the adsorption capacity for MB by several adsorbents

\begin{tabular}{lll}
\hline Adsorbent & Adsorption capacity $\left(\mathrm{mg} \mathrm{g}^{-1}\right)$ & Reference \\
\hline AIKL & 200.00 & This work \\
Lignin-chitosan composite & 36.25 & 25 \\
Lignin-silica composite & 60.00 & 34 \\
Lignin-based hydrogels & 69 to 629 & 35 \\
Sawdust & $27.78-59.17$ & 36 \\
Kapok fiber & 110.13 & 14 \\
Platanus orientalis leaf & 114.94 & 37 \\
Luffa cylindrica fibers & 122.00 & 38 \\
Activated carbon prepared from lignin & 147.00 & 27 \\
Banana pseudostem biochar & 146.23 & 39
\end{tabular}

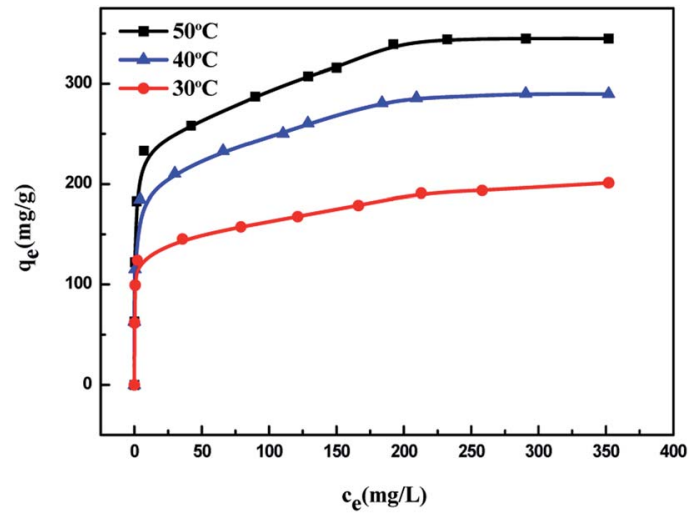

Fig. 8 Effect of the temperature on the adsorption of MB.

AIKL. As we know, the high-energy water molecules were released from the cavity upon polycyclic aromatic compounds, leads to the endothermic reaction. Increasing the temperature could reduce of hydration layer remarkably, resulting the enhance of hydrophobic interaction which could increase the adsorption capacity.

This opinion could be further confirmed by the positive value of the entropy change $(\Delta S)$. It indicates that the adsorption of MB on AIKL was completely driven by the entropic increase (Table 4) which is a typical characteristic of hydrophobic interaction in adsorption. ${ }^{41}$ Thus, the hydrophobic interaction could be considered as one of the main binding contributions for the adsorption of MB onto AIKL.

3.4.2. Effect of ionic strength. The sodium chloride as a stimulator is commonly used in dying processes, and the concentration of salt in industrial MB wastewater is high. ${ }^{40}$

Table 4 Thermodynamic parameters for the adsorption of MB onto AIKL

\begin{tabular}{|c|c|c|c|c|}
\hline \multirow{2}{*}{$\begin{array}{l}\Delta H \\
\left(\mathrm{~kJ} \mathrm{~mol}^{-1}\right)\end{array}$} & \multirow{2}{*}{$\begin{array}{l}\Delta S \\
\left(\mathrm{~J} \mathrm{~mol}^{-1} \mathrm{~K}^{-1}\right)\end{array}$} & \multicolumn{3}{|c|}{$\Delta G\left(\mathrm{~kJ} \mathrm{~mol}^{-1}\right)$} \\
\hline & & $303 \mathrm{~K}$ & $313 \mathrm{~K}$ & $323 \mathrm{~K}$ \\
\hline 74.3996 & 10.8422 & -11.7051 & -12.4357 & -13.1937 \\
\hline
\end{tabular}

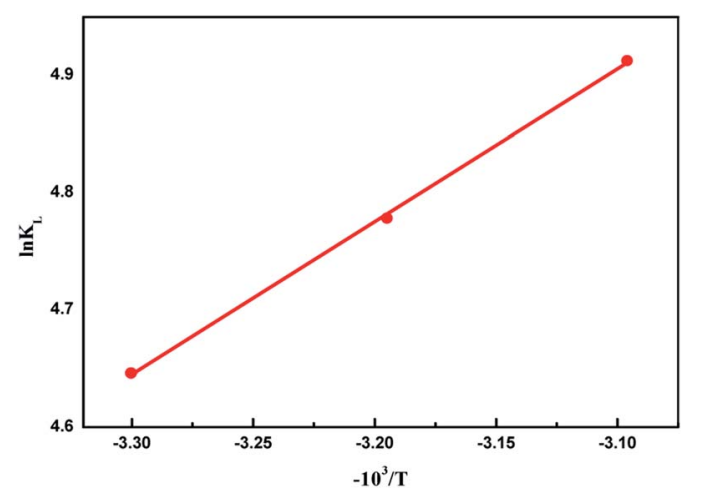

Fig. 9 Thermodynamic plots for the adsorption of MB onto AIKL.

Therefore, the effect of ionic strength on the removal of MB by AIKL was invested at different concentrations of NaCl. As shown in Fig. 10, at first, the adsorption capacity decreased slightly with the increase of ionic strength, but then increased sharply when the concentration exceeded $0.316 \mathrm{~mol} \mathrm{~L}^{-1}$.

When the $\mathrm{NaCl}$ was added to the solution, it would screen the charges of MB and AIKL, and thus inhibits the cation-anion interactions between them. So, $\mathrm{NaCl}$ plays an adverse effect on the electrostatic attraction for MB adsorption. When enough

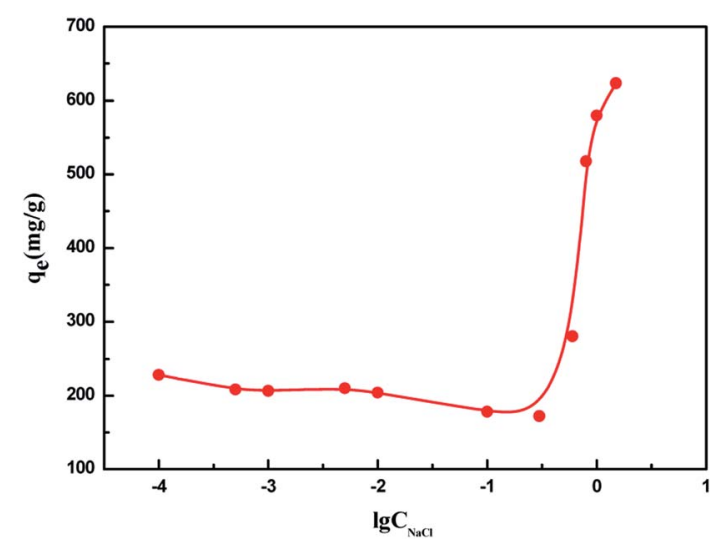

Fig. 10 Effects of ionic strength ( $\mathrm{NaCl}$ concentration) on the adsorption of $\mathrm{MB}$. 
salt was added, the electrostatic attraction between $\mathrm{MB}$ and AIKL becomes negligible. However, the adsorption amount increased obviously. It indicated that there must exist some other important driving forces besides the electrostatic interaction. As we know, the increase of ionic strength could reduce the barrier of the hydration layer, ${ }^{43}$ and the hydration layer barriers the combination of MB and AIKL molecules by hydrophobic interaction. Thus, the experimental results further proved that the hydrophobic interaction was beneficial to the adsorption.

\subsection{Strengthening mechanism of acetone fractionation}

As discussed in the effect of solvent conditions above on, the electrostatic attraction and hydrophobic interaction were the two main forces of adsorption. As we know, after acetone fractionation, due to the reduction of phenolic hydroxyl $(-\mathrm{OH})$ and carboxyl groups $(-\mathrm{COOH})$, AIKL has fewer negative charges than ASKL and KL. ${ }^{44}$ Interestingly, AIKL with fewer negative charge has much higher adsorption capacity. Thus, the electrostatic attraction may not play a central role for the adsorption between lignin and MB. While, the hydrophobic interaction may play the dominant role.

The band around $1460 \mathrm{~cm}^{-1}$ of these lignin samples, ascribed to vibration of aromatic ring, all shifted to low wavenumber when $\mathrm{MB}$ was adsorbed on them. And the main aromatic peaks of these samples, before and after adsorption, were listed in Table 5. The shifts in the main aromatic peak position to lower wavenumber in vibrational spectroscopy provides direct evidence for $\pi-\pi$ interactions. Moreover, the peaks around $1460 \mathrm{~cm}^{-1}$ of AIKL caused by MB adsorption shift about $6.04 \mathrm{~cm}^{-1}$, while, it is only $1.52 \mathrm{~cm}^{-1}$ for KL and 0.46 for ASKL. This information indicated that the $\pi-\pi$ interactions of AIKL-MB is stronger than that KL-MB.

Indeed, the $\pi-\pi$ interactions between AIKL and MB not only can be confirmed by the results of FT-IR, but also could be explained reasonably (Fig. 11). The strengthening mechanisms of acetone fractionation were schematically described in Fig. 12. The MB is an ideal planar molecule which has $\mathrm{C}-\mathrm{C}$ double bonds and contains $\pi$-electrons. The aromatic rings of lignin are oriented preferentially parallel to the surface. Also, the associated KL complexes is a flexible lamellar configuration. Obviously, this spatial structure feature of lignin could contribute to the formation of $\pi-\pi$ stacking between MB and lignin. The similar $\pi-\pi$ electron donor acceptor interaction also

Table 5 The aromatic skeletal vibration (around $1460 \mathrm{~cm}^{-1}$ ) of different lignin samples before and after adsorption of MB

Before and after adsorbed by AIKL

\begin{tabular}{lllr}
\hline Adsorbent & $\begin{array}{l}\text { Unloaded by } \\
\text { MB }\left(\mathrm{cm}^{-1}\right)\end{array}$ & $\begin{array}{l}\text { Loaded by } \mathrm{MB} \\
\left(\mathrm{cm}^{-1}\right)\end{array}$ & $\Delta\left(\mathrm{cm}^{-1}\right)$ \\
\hline KL & 1461.44 & 1459.92 & -1.52 \\
ASKL & 1462.54 & 1463.00 & 0.46 \\
AIKL & 1458.67 & 1452.63 & -6.04
\end{tabular}

(a)

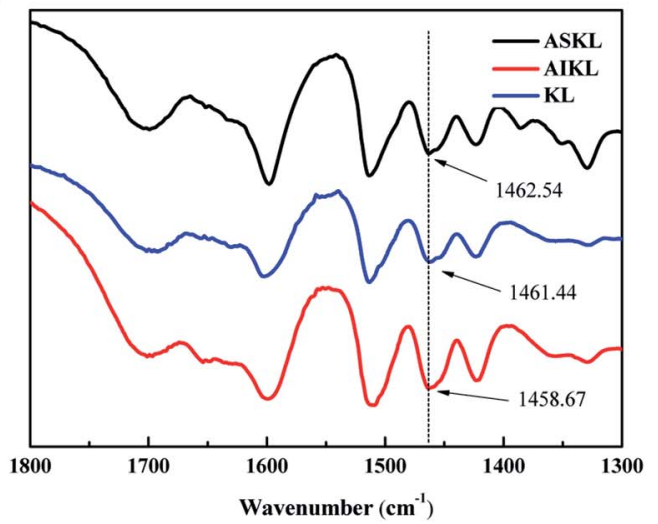

(b)

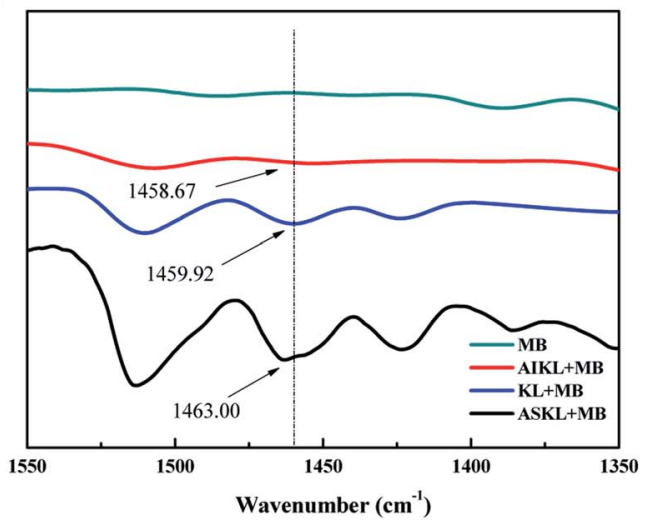

Fig. 11 FTIR spectra of KL, ASKL and AIKL (a); and KL, ASKL and AIKL after MB loading (b).

play an important role when MB were adsorbed onto graphene oxide $^{45}$ and carbon nanotubes. ${ }^{\mathbf{4 2}}$

It is reported that, the lignin after fractionation by acetoneaqueous solution of different concentrations, the molecular weight of lignin decreases with the decrease of acetone concentration, and the content of phenolic hydroxyl group and carboxyl group increases. ${ }^{\mathbf{4 4 , 4 6 , 4 7}}$ And the AIKL with higher molecular weight after fractionation tend to have more aromatic groups. ${ }^{48}$ On the one side, more aromatic groups could provide more effective adsorption sites for the reception of $\mathrm{MB}$ by $\pi-\pi$ interactions. On the other side, less phenolic hydroxyl and carboxyl groups could reduction the hydration layer which was beneficial to the $\pi-\pi$ interaction between AIKL and MB

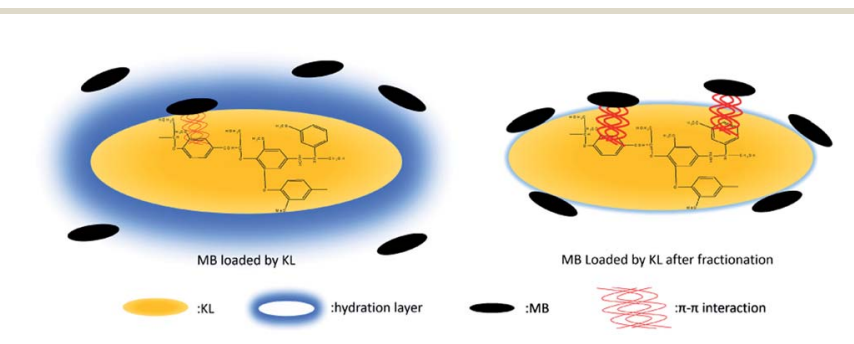

Fig. 12 Schematic illustration of enhanced adsorption after acetone grading. 
aromatic rings. By the promotion of these two reasons, the performance of AIKL has been significantly improved.

\section{Conclusions}

In summary, the surface properties of KL were obviously improved by solvent fractionation treatment. The reduction of hydration layer on AIKL surface was beneficial to the $\pi$-electron coupling between the aromatic molecules of MB and AIKL. The increase of ionic strength and temperature would cause the reduction of hydration layer which lead to the increase of adsorption capacity. Compared to other adsorbents, AIKL has advantage of inherent adsorption ability for aromatic compounds through stronger $\pi-\pi$ interaction. Therefore, the fractionated AIKL adsorbents derived from abundant, low-cost and non-toxic KL, would be a promising adsorbent for aromatic pollutants removal in wastewater.

\section{Conflicts of interest}

There are no conflicts to declare.

\section{Acknowledgements}

We are grateful for financial support from the National Natural Science Foundation of China (21808047), the High-level Personnel Foundation of Hebei Province (A2017002032), the Outstanding Young Scholars Program in Universities of Hebei, China (BJ201615), the Natural Science Foundation of Hebei, China (B2017202087), the Research Fund Program of Guangdong Provincial Key Lab of Green Chemical Product Technology, China (GC201805).

\section{References}

1 X. Wang, C. Jiang, B. Hou, Y. Wang, C. Hao and J. Wu, Chemosphere, 2018, 206, 587-596.

2 H. Li, S. Xu, J. Du, J. Tang and Q. Zhou, RSC Adv., 2019, 9, 941-942.

3 H. Deng, J. Lu, G. Li, G. Zhang and X. Wang, Chem. Eng. J., 2011, 172, 326-334.

4 J. Yi and L. Zhang, Bioresour. Technol., 2008, 99, 2182-2186. 5 G. Li, W. Zhu, C. Zhang, S. Zhang, L. Liu, L. Zhu and W. Zhao, Bioresour. Technol., 2016, 206, 16-22.

6 K. Jung, B. H. Choi, M. Hwang, T. Jeong and K. Ahn, Bioresour. Technol., 2016, 219, 185-195.

7 M. T. Yagub, T. K. Sen, S. Afroze and H. M. Ang, Adv. Colloid Interface Sci., 2014, 209, 172-184.

8 L. Shi, D. Wei, H. H. Ngo, W. Guo, B. Du and Q. Wei, Bioresour. Technol., 2015, 194, 297-304.

9 C. Li, Y. He, L. Zhou, T. Xu, J. Hu, C. Peng and H. Liu, RSC Adv., 2018, 8, 41986-41993.

10 B. Li, J. Lv, J. Guo, S. Fu, M. Guo and P. Yang, Bioresour. Technol., 2019, 275, 360-367.

11 Y. Jin, C. Zeng, Q. Lü and Y. Yu, Int. J. Biol. Macromol., 2019, 123, 50-58.
12 J. Liu, Y. Du, W. Sun, Q. Chang and C. Peng, RSC Adv., 2019, 9, 22513-22522.

13 C. Chen, S. Mi, D. Lao, P. Shi, Z. Tong, Z. Li and H. Hu, RSC Adv., 2019, 9, 22248-22262.

14 Y. Liu, J. Wang, Y. Zheng and A. Wang, Chem. Eng. J., 2012, 184, 248-255.

15 M. S. Ur Rehman, I. Kim and J. Han, Carbohydr. Polym., 2012, 90, 1314-1322.

16 A. Bhatnagar and M. Sillanpaa, Chem. Eng. J., 2010, 157, 277296.

17 X. Han, W. Wang and X. Ma, Chem. Eng. J., 2011, 171, 1-8.

18 S. Zhao and T. Zhou, Bioresour. Technol., 2016, 219, 330-337.

19 M. T. Islam, R. Saenz-Arana, C. Hernandez, T. Guinto, M. A. Ahsan, H. Kim, Y. Lin, B. Alvarado-Tenorio and J. C. Noveron, RSC Adv., 2018, 8, 32545-32557.

20 M. Rafatullah, O. Sulaiman, R. Hashim and A. Ahmad, J. Hazard. Mater., 2010, 177, 70-80.

21 J. Li, Y. Li, Y. Wu and M. Zheng, J. Hazard. Mater., 2014, 280, 450-457.

22 Y. Ge and Z. Li, ACS Sustainable Chem. Eng., 2018, 6, 71817192.

23 X. Wang, Y. Wang, S. He, H. Hou and C. Hao, Ultrason. Sonochem., 2018, 40, 221-229.

24 Z. Li, Y. Kong and Y. Ge, Chem. Eng. J., 2015, 270, 229-234.

25 A. B. Albadarin, M. N. Collins, M. Naushad, S. Shirazian, G. Walker and C. Mangwandi, Chem. Eng. J., 2017, 307, 264-272.

26 V. Nair, A. Panigrahy and R. Vinu, Chem. Eng. J., 2014, 254, 491-502.

27 A. Kriaa, N. Hamdi and E. Srasra, Russ. J. Phys. Chem. A, 2011, 85, 279-287.

28 Q. Feng, H. Cheng, F. Chen, X. Zhou, P. Wang and Y. Xie, J. Wood Chem. Technol., 2016, 36, 173-181.

29 J. Li, H. Li, Z. Yuan, J. Fang, L. Chang, H. Zhang and C. Li, Int. J. Biol. Macromol., 2019, 135, 1171-1181.

30 T. Aro and P. Fatehi, ChemSusChem, 2017, 10, 1861-1877.

31 H. Sadeghifar and D. S. Argyropoulos, ACS Sustainable Chem. Eng., 2015, 3, 349-356.

32 Y. Qian, Y. Deng, X. Qiu, H. Li and D. Yang, Green Chem., 2014, 16, 2156.

33 S. Sen, S. Patil and D. S. Argyropoulos, Green Chem., 2015, 17, 1077-1087.

34 T. M. Budnyak, S. Aminzadeh, I. V. Pylypchuk, D. Sternik, V. A. Tertykh, M. E. Lindström and O. Sevastyanova, J. Environ. Chem. Eng., 2018, 6, 4997-5007.

35 J. Domínguez-Robles, M. S. Peresin, T. Tamminen, A. Rodríguez, E. Larrañeta and A. Jääskeläinen, Int. J. Biol. Macromol., 2018, 115, 1249-1259.

36 F. Ferrero, J. Hazard. Mater., 2007, 142, 144-152.

37 M. Peydayesh and A. Rahbar-Kelishami, J. Ind. Eng. Chem., 2015, 21, 1014-1019.

38 H. Demir, A. Top, D. Balkose and S. Ulku, J. Hazard. Mater., 2008, 153, 389-394.

39 S. Liu, J. Li, S. Xu, M. Wang, Y. Zhang and X. Xue, Bioresour. Technol., 2019, 282, 48-55.

40 H. Chen, J. Zhao and G. Dai, J. Hazard. Mater., 2011, 186, 1320-1327. 
41 M. Chen, Y. Chen and G. Diao, J. Chem. Eng. Data, 2010, 55, 5109-5116.

42 J. Ma, F. Yu, L. Zhou, L. Jin, M. Yang, J. Luan, Y. Tang, H. Fan, Z. Yuan and J. Chen, ACS Appl. Mater. Interfaces, 2012, 4, 5749-5760.

43 X. P. Ouyang, Y. H. Deng, Y. Qian, P. Zhang and X. Q. Qiu, Biomacromolecules, 2011, 12, 3313-3320.

44 H. Sadeghifar, T. Wells, R. K. Le, F. Sadeghifar, J. S. Yuan and A. Jonas Ragauskas, ACS Sustainable Chem. Eng., 2016, 5, 580-587.
45 T. Wu, X. Cai, S. Tan, H. Li, J. Liu and W. Yang, Chem. Eng. J., 2011, 173, 144-149.

46 J. Domínguez-Robles, T. Tamminen, T. Liitiä, M. S. Peresin, A. Rodríguez and A. Jääskeläinen, Int. J. Biol. Macromol., 2018, 106, 979-987.

47 A. S. Jääskeläinen, T. Liitiä, A. Mikkelson and T. Tamminen, Ind. Crops Prod., 2017, 103, 51-58.

48 L. An, G. Wang, H. Jia, C. Liu, W. Sui and C. Si, Int. J. Biol. Macromol., 2017, 99, 674-681. 